\title{
Altivez e resistência na representação do Outro em Dulce Sudor Amargo de Miguel Rio Branco
}

Pride and resistance at the other representation in Dulce Sudor Amargo of Miguel Rio Branco

\begin{abstract}
RESUMO
Este artigo tem como objetivo analisar algumas fotografias de Miguel Rio Branco que, diferente de muitos de seus predecessores que atuaram na documentação de determinados grupos sociais no Brasil, buscou romper com a representação do Outro segundo uma visão externa, estereotipada e unívoca. Ao documentar grupos marcadamente oprimidos como prostitutas e moradores de ruas, ele produziu não apenas imagens libertas do olhar romântico predominante entre fotógrafos viajantes que percorreram o território brasileiro a partir da segunda metade do século XIX, mas, sobretudo, narrativas visuais que transcendem a função exclusivamente informativa e, por vezes, denuncista das fotografias dos dramas sociais do país realizadas em meados do século XX por fotojornalistas nacionais ou estrangeiros.
\end{abstract}

Palavras-chave: Fotografia; Dulce Sudor Amargo; Miguel Rio Branco.

\begin{abstract}
This article aims to analyse some photographs of Miguel Rio Branco who, unlike theirs predecessors in the documentation of certain social groups in Brazil, sought to break the Other's repress oppressed like prostitutes and homeless, he produced not only images free from the romantic and exotic eyes prevalent among the pioneers of photography who travelled the Brazilian territory from the second half of nineteenth century, but also visuals narratives that transcend the informative and complaining role of the social drama's photographs made by both national and foreign photojournalists through the twentieth century.
\end{abstract}

Keywords: Photography; Dulce Sudor Amargo; Miguel Rio Branco. 


\section{INTRODUÇÃO}

No livro "Fotografia Brasileira Contemporânea", publicado por ocasião da exposição homônima, realizada em Frankfurt, em 1994, o museólogo e curador Paulo Herkenhoff analisa a história recente da fotografia brasileira e observa que durante a ditadura de 1964 a cultura no país voltou-se para a formulação de estratégias políticas para fazer frente ao regime militar, como a tática prevalecente da denúncia sutil através do fotojornalismo. Ele observa, porém, que com a lenta distensão política no final da década de 1970 a fotografia começou a se abrir para diferentes formas de expressão, se libertando "daquela tarefa de revolta e defesa da liberdade" (HERKENHOFF, 1994, p. 43).

Esta exposição apresentou três gerações de fotógrafos, cujas imagens, segundo seu curador, "não pretendem ser um retrato do Brasil, mas o recorte de uma atitude". Nela, Herkenhoff aponta Miguel Rio Branco (1946 -), juntamente com Claudia Andujar (1931 -) e Mário Cravo Neto (1947 - 2009), como integrantes da primeira geração que, na década de 1970, mostrou uma "atitude de experimentação que se expande, alcançando seu ponto principal na atualidade". Além disso, Herkenhoff ainda afirma que esses fotógrafos "vivem a busca incessante da alteridade, da apreensão desse ser incomensurável, o Outro", ressaltando o fato de que, numa sociedade complexa como a brasileira, com sua violenta história, sua formação étnica e sua estrutura de classes, a cultura do século XX mantém um traço de busca de identidade nacional contra um passado colonial (HERKENHOFF, 1994, p. 43-44).

Nesse sentido, a motivação deste artigo, se deu pela tentativa de compreender tal atitude pioneira de Miguel Rio Branco que poderia ser identificada como fundadora de uma nova fase na fotografia brasileira. Afinal, além de explorar novas estratégias estéticas que flexibilizam as fronteiras entre arte e documentação, seus trabalhos marcariam um momento singular na história da fotografia no Brasil em que os sujeitos fotografados - moradores de rua, pequenos comerciantes e, principalmente, prostitutas - vivem um processo dialógico de construção de sua identidade.

Assim, esta "atitude de experimentação" poética e politicamente engajada para construção da representação do Outro, que o coloca em estado de resistência frente às adversidades da vida, contrastaria não apenas com os retratos dos "tipos sociais" realizados sob o olhar exótico e romântico dos fotógrafos viajantes que percorreram o território brasileiro a partir da segunda metade do século XIX, mas também com os registros de fotojornalistas nacionais e estrangeiros que atuaram nas revistas e jornais em meados do século XX documentando e denunciando os dramas sociais, a pobreza e violência no país. Por isso, se torna necessária aqui uma breve apresentação histórica dessas documentações no Brasil antes de se analisar os trabalhos de Rio Branco. 


\section{BREVE HISTÓRICO DA DOCUMENTAÇÃO NO BRASIL}

O advento da fotografia se deu no início do século XIX, período marcado por uma concepção de História inspirada na filosofia positivista, na qual o conceito de documento histórico estava diretamente associado à noção de prova. Esta época era considerada como a "era da revolução", em razão das grandes revoluções sociais e políticas que aconteciam nos Estados Unidos e na Europa, notadamente na França. É então neste cenário de revolução e progresso científico que esse novo tipo de imagem surgiu, juntamente com a rápida industrialização, o crescimento das ferrovias, uma acelerada concentração de pessoas nas zonas urbanas vindas das áreas rurais, uma crescente estratificação da sociedade em grupos de operários, comerciantes e um pequeno número de magnatas.

O conceito de fotografia enquanto imagem objetiva e utilitária estava em consonância com a racionalidade instrumental, a mecanização e o espírito capitalista da época. Desde a divulgação de sua invenção, o seu suposto poder de reproduzir com exatidão a realidade the assegurou um caráter essencialmente documental. Em seu discurso realizado no dia três de julho de 1839, François Arago anunciou, na Câmara dos Deputados, em Paris, a invenção da fotografia por Louis Jacques Mandé Daguerre e Joseph Nicéphore Niépce (já falecido na época), ressaltando as qualidades técnicas e as capacidades deste novo tipo de imagem (o daguerreótipo) de contribuir com os mais variados campos da ciência e da arte. Na ocasião Arago afirmou que:

Uma vez que esta invenção segue as leis da geometria, será possível restabelecer com um pequeno número de determinados fatores o tamanho exato dos mais altos pontos das estruturas mais inacessíveis (ARAGO, 1980, p. 17).

Nesse contexto, a fotografia foi promovida pelas sociedades industrializadas como um dos meios mais apropriados para registrar as transformações físicas das cidades, as guerras, as revoluções, os desastres naturais, as condições da vida cotidiana dos homens no mundo, bem como para representar a visão científica sobre as plantas e animais pesquisados pelas ciências biológicas, os sintomas de doenças tratadas pela medicina, os fenômenos dos astros e corpos celestes estudados pela astronomia e sobre tantos outros objetos de pesquisa nos mais variados campos do saber para os quais a fotografia tornou-se uma das principais ferramentas de análise.

A nitidez das imagens, a organização em ensaios ou séries e os métodos de catalogação e arquivamento em temas específicos eram algumas das exigências destas documentações que, a partir de meados do século XIX, buscaram descobrir, registrar e, muitas das vezes, servir com instrumento de colonização e dominação das mais diversas regiões a fim de construir uma "enciclopédia visual" do mundo. Como destaca Souza (2000), os exploradores europeus, por exemplo, se dedicaram às missões fotográficas com objetivos científicos na África e também 
com intuito de documentar o ambiente e as populações principalmente na Ásia e no Oriente Médio, visando fornecer imagens "exóticas" bem ao gosto das sociedades europeias da época que fomentavam, por sua vez, o comércio de postais ilustrados com retratos e vistas dessas regiões, sobretudo do Egito

No Brasil, assim como em outros países, a fotografia substituiu os retratos pictóricos e despertou o interesse das classes mais abastadas da sociedade pelas novas formas de representação que, comparadas à pintura, apresentavam-se muito mais próximas do real. Dessa forma, não tardou para que os primeiros fotógrafos estrangeiros, chegando ao país, oferecessem seus serviços como retratistas por meio de anúncios nos jornais locais.

Beneficiando-se dos novos processos do colódio úmido e, posteriormente, das placas secas já industrializadas, esses fotógrafos dedicaram-se ao longo da segunda metade do século XIX e começo do século XX à produção de imagens panorâmicas das cidades e paisagens naturais brasileiras, bem como de retratos dos "tipos sociais" do país. Essas imagens serviam não apenas como objeto de contemplação, mas também como instrumento de análise da realidade da população e do território do Brasil, dado que a fotografia era tomada como uma testemunha da verdade. No entanto, os modos de produção fotográfica nessa época já evidenciavam a capacidade do medium de não apenas registrar "realisticamente", como também de construir representações fictícias que, não raro, traziam a marca de seu autor e o seu olhar romântico sobre a realidade, reforçando assim a ideologia do exotismo - característica marcante nos relatos dos viajantes europeus pelas terras brasileiras no século XIX.

Sobre, por exemplo, os retratos feitos em ambiente externo pelo francês Victor Frond (18211881), as historiadoras Ângela Magalhães e Nadja Peregrino (2004, p. 26) neles identificam uma representação idealizada do trabalho escravo "onde o negro é documentado na paisagem que circunda a casa grande em cenas plácidas, destituídas de qualquer indício de conflitos". Já nas imagens construídas em estúdio fica evidente a encenação no conjunto de retratos de índios com objetos da vida indígena produzido por Marc Ferrez (1843-1923) e na "collecção de typos de pretos" realizada por José Christiano de Freitas Henriques Junior (1832-1902) que registrava seus personagens em poses montadas diante de um fundo neutro ou de cenários pintados remetendo ao imaginário europeu. Assim, diante de um mercado em plena expansão no que se refere ao consumo de imagens exóticas, comercializadas à época principalmente no formato cartãopostal, a venda destas fotografias dependiam, salienta o fotógrafo e historiador Boris Kossoy, de uma produção "bem ao gosto da antropologia social e das teses racistas em voga na Europa" (KOSSOY, 2002, p. 174).

A fotografia ganha definitivamente relevância nas páginas das revistas ilustradas brasileiras que começam a perceber a sua força expressiva e, sobretudo, o seu poder de comunicação. Do final dos 
anos 1930 até meados dos anos 1940, um novo e importante grupo de fotógrafos chegou ao Brasil, trazendo uma contribuição inestimável, tanto do ponto de vista técnico quanto do estético. Alguns destes fotógrafos estrangeiros vão se juntar a um grupo de fotógrafos brasileiros sintonizados com o movimento fotográfico internacional a fim de formarem a equipe de fotografia da revista O Cruzeiro, cujos trabalhos valorizarão um Brasil até então desconhecido (FERNANDES JUNIOR, 2003). Jean Manzon (1915-1990), Pierre Verger (1902-1996), Marcel Gautherot (1910-1996), Ed Keffel, Peter Scheier (1908-1979), José de Medeiros (1921-1990), Luís Carlos Barreto (1928-), entre outros, irão traçar um novo caminho para a documentação fotográfica brasileira, a qual estaria voltada dominantemente para o registro do brasileiro, sua cultura, suas crenças e seu cotidiano de trabalho e lazer.

Nessa época, a fotografia brasileira buscou captar a realidade do homem nas várias regiões do país, explorando temas como, por exemplo, as tribos indígenas, seu cotidiano e rituais, os jangadeiros do nordeste e os seringueiros do norte, as comunidades dos pampas no sul, os operários nas grandes metrópoles, os flagelados da seca, os sem-terra, os rituais afro-brasileiros etc.

De acordo com o historiador e crítico de arte Tadeu Chiarelli (1999, p. 132), ainda no período em que a arte modernista estava fixada no mapeamento da paisagem humana brasileira, alguns fotógrafos já enveredavam para este mesmo foco, porém divididos em duas tendências. Enquanto uns seguiam "a preocupação dos pintores mais importantes da época", outros, acompanhavam "uma tendência típica da 'fotografia verdade' internacional". Chiarelli, no entanto, observa que, quando a arte brasileira se volta, nos anos 1950, para o discurso de suas especificidades e/ou para a exploração de seus limites, esta fotografia que buscava captar a realidade do homem local ganhou força e tornou-se

[...] se não a única vertente fotográfica existente no país, pelo menos aquela que teria encontrado um nicho definido, embora nublado, pelo fato de que, dentro dela, se justapõem a questão documental e a expressão artística (CHIARELLI, 1999, p. 132).

Os fotodocumentaristas se debruçaram sobre os mais variados temas e "a razão de ser da própria fotografia passou a ser, no Brasil, o registro - ou a construção - da identidade do brasileiro". Nesse sentido, ao mapear o Brasil humano e tornar visível as suas várias expressões e os modos de vida, "a fotografia brasileira de fato", pergunta-se Chiarelli, "identificou o brasileiro, ou o homem brasileiro ficou identificado apenas através da imagem que este tipo de fotografia criou?" (CHIARELLI, 1999, p. 132).

Mais do que registrar a realidade do Brasil e do brasileiro, muitos desses fotógrafos ajudaram a construir esteticamente a imagem da nação a partir não apenas de um olhar estrangeiro, mas também de uma busca pelo mapeamento da paisagem humana brasileira, que era, desde os anos 1930, uma tendência da arte modernista brasileira, notadamente da pintura, caracterizada fortemente pela preocupação em criar uma iconografia nacional. 
A partir dos anos 1960, como consequência do processo de industrialização, o Brasil testemunhou um período de crescimento nos centros urbanos e de aumento do êxodo rural, com o deslocamento de grande número de famílias para regiões mais ricas, como Rio de Janeiro e São Paulo, as quais já não conseguiam oferecer uma infraestrutura adequada àqueles que chegavam, em sua maioria, do Nordeste brasileiro, provocando um cenário repleto de problemas sociais nas capitais do país, assim como nas zonas rurais que sofriam pelo esquecimento e descaso do poder público. Além disso, este período foi também marcado por diversos conflitos políticos e ideológicos, devido à instauração de uma ditadura militar em 1964, cujo clima de repressão acabou motivando uma atuação cada vez mais crítica e politizada por parte de intelectuais e artistas que passaram a extrair da realidade as suas temáticas.

Ao analisar a produção fotográfica dessa época, Kossoy e Entler (1996) afirmam que "o diletantismo estetizado dos fotoclubes e os temas amenos da maioria das revistas ilustradas perdem espaço para uma produção mais engajada na denúncia dos problemas sociais". Os pesquisadores destacam, além do Jornal do Brasil e do Jornal da Tarde, a revista Realidade como "aquela que foi uma das mais importantes publicações desse período" e ainda observam que, de um modo geral, a imprensa passou a dedicar mais espaço às imagens (KOSSOY, ENTLER, 1996).

Diante de um longo período de censura à imprensa e às atividades artísticas em geral durante a ditadura militar os documentaristas tiveram uma atuação cada vez mais crítica e politizada, utilizando a fotografia como representação fiel e objetiva da realidade, portanto, uma poderosa arma de denúncia contra desigualdades sociais e de luta pelos direitos civis. Entretanto, com o fim da ditadura e o início do processo de redemocratização em meados dos anos 1980, percebe-se o surgimento de produções experimentais de fotógrafos que continuam a tratar de questões sociais, porém com novas abordagens que dissociam seus trabalhos da exclusiva função informativa e, por vezes, denuncista da fotografia na imprensa.

Assim, a partir desse breve panorama histórico que abordou tanto as diferentes formas de representação do Outro quanto o conceito da fotografia como registro ou construção da realidade, este estudo propõe, a seguir, apresentar resumidamente a biografia do fotógrafo Miguel Rio Branco e o contexto de produção do seu primeiro livro intitulado Dulce Sudor Amargo (1985) para, posteriormente, analisar algumas de suas imagens. 


\section{O FOTÓGRAFO E O LIVRO DULCE SUDOR AMARGO}

Miguel Rio Branco nasceu em 1946 e viveu até os 3 anos de idade em Las Palmas de Gran Canarias, na Espanha. Filho de diplomatas, desde cedo ele se acostumou com mudanças, tendo passado a sua infância nas cidades de Buenos Aires, Lisboa e Rio de Janeiro. Entre os anos 1961 e 1963, morou na Suíça, onde estudou e desenvolveu os seus primeiros trabalhos como ilustrador de um jornal local e cenógrafo de uma peça teatral. Nessa época, tomou gosto pelo desenho e pela pintura e realizou, em 1964, a sua primeira exposição, Paintings and drawings, na Galeria Anlikerkeller, em Berna. Neste mesmo ano, mudou-se com os seus pais para Nova York e fez um curso básico de fotografia durante um mês no New York Institute of Photography. A partir de então, passou a utilizar a câmera fotográfica com mais constância, tendo realizado uma série de fotografias nas ruas desta cidade que serviram, principalmente, como colagens em suas pinturas. Esse interesse pela articulação de diferentes mídias será desenvolvido ao longo de toda a sua carreira, sobretudo através livros fotográficos ${ }^{[1]}$ e instalações multimídias realizados no anos 1980 e 1990, o que the tornaram um dos principais nomes da fotografia e da arte contemporânea no Brasil.

De volta ao Brasil, ingressou, em 1968, na Escola Superior de Desenho Industrial (ESDI), mas abandonou o curso após seis meses de estudo. Ele tinha decidido que, para criar, não precisava fazer cursos acadêmicos. Assim, a sua carreira voltou-se à fotografia e ao cinema, atividades que surgiram praticamente ao mesmo tempo e Ihe garantiram a subsistência durante os anos 1970. No começo dessa década, retornou à Nova York para estudar fotografia na School of visual arts. Entretanto, como já havia feito no passado, ele abandonou novamente os estudos por achar que a prática valeria mais a pena do que passar três anos nesse curso. Em 1972, com a morte de sua mãe, Rio Branco voltou ao Rio de Janeiro e dedicou-se, principalmente, ao cinema, trabalhando, ao longo de toda essa década, em muitos filmes como diretor de fotografia e câmera.

Após atuar como artista plástico, desenhando e pintando nos anos 1960, e como diretor de fotografia e realizador em cinema na década seguinte, Rio Branco se envolverá mais intensamente com o documentário fotográfico e o mercado editorial do jornalismo no começo dos anos 1980, quando ele tem algumas de suas produções reconhecidas e distribuídas pela Magnum Photos e publicadas em diversas revistas como Stern, National Geographic, Geo, Aperture, Photo Magazine, entre outras.

Embora tenha feito, em 1972, alguns contatos com a Magnum, foi somente em 1980, após apresentar a essa agência um ensaio produzido, um ano antes, no Pelourinho, em Salvador, que Rio Branco tornou-se o seu correspondente no Brasil. Ele havia acabado de realizar um trabalho para a revista Geo sobre meninos de rua em vários lugares do Brasil, durante o qual conheceu a comunidade do Maciel, localizada no Pelourinho., região que então passou a frequentar e fotografar 
regularmente a região, período em que fotografou ruas, bares e casarões coloniais em situação de forte degradação, além de retratar crianças, homens e, sobretudo, um grupo de mulheres que trabalhavam como prostitutas. Assim, se este ensaio foi primeiramente produzido com o objetivo de compor as páginas de uma revista dedicada a publicações sobre meio ambiente, geografia, história e cultura mundiais para um público inclinado a temas "exóticos", posteriormente, parte de suas fotografias ganham outra carga semântica ao integrar a narrativa do livro Dulce Sudor Amargo, publicado somente em 1985.

Dessa forma, cabe refletirmos sobre o contexto não apenas de produção do livro, mas também do mercado editorial do fotojornalismo internacional, mercado historicamente marcado por publicações que, embora amparadas no discurso da suposta neutralidade da fotografia, não apenas registram a realidade de países "distantes" e seus habitantes, mas, sobretudo, interpretam e constroem mundos a partir de modelos hegemônicos de representação.

Em uma série de ensaios intitulados Desaprendendo Momentos Decisivos (2019) a pesquisadora israelense Ariella Azoulay questiona as origens modernas da fotografia e sua relação com o colonialismo e a violência imperial. Ela afirma que a "fotografia, entre outras tecnologias, estava enraizada nas estruturas imperiais de poder e violência na forma de direitos exercidos sobre o outro" (AZOULAY, 2019, p. 120). Fazendo uma breve revisão histórica, Azoulay lembra que, com base no entendimento da fotografia como um procedimento de reprodução neutra da realidade, ela passou a ser usada por aqueles que dispunha destes meios (nações imperialistas industrializadas) para registrar o mundo das pessoas, mesmo sem a permissão dos donos desses mundos, geralmente em regiões como Ásia, África e América Latina. Em sua teoria, esse suposto "direito" de dissecar e estudar por meio de fotografias o mundo das pessoas - direito de exigir que tudo seja mostrado e exibido ao olhar - é por ela considerado um tipo de "violência do ver", já que pressupõe um suposto direito universal de ver que comtemplaria "todos", mas não respeita o direito de as comunidades fotografadas poderem rejeitar que seus corpos e objetos sejam indiscriminadamente acessados e representados em imagens.

A pesquisadora escreve ainda que, "desde o estágio inicial da fotografia, presumia-se que os fotografados, e não os espectadores, deveriam fornecer recurso e mão de obra barata para esta empreitada fotográfica em larga escala", sendo considerados figurantes, atores secundários ou matéria-prima, ao passo que os fotógrafos constituiriam "a espinha dorsal da história da fotografia" (idem, p. 131). Em seguida, ela então destaca a relação desenvolvida entre a mais prestigiada das agências de fotografia, a Magnum Photos, e os fotógrafos que, como Miguel Rio Branco, para ela trabalharam. Para Azoulay, estes fotógrafos atuavam como "intermediários entre os fotografados - objetos da sua arte - e outros agentes imperiais" e, mesmo que não fossem empreendedores imperiais milionários nem visassem ao lucro, eles se beneficiavam da 
dominação imperial dos mercados fotográficos, podendo ir "onde quisessem" no mundo e ainda reivindicar a autoria de fotografias que exibiam pessoas as quais não participavam do lucro de suas publicações. Assim, dispara Azoulay:

Ao ser concedido o direito de privar os outros do seu quinhão na fotografia,
fotógrafos não necessariamente enriqueceram, mas possibilitaram que grandes
corporações, coleções e instituições lucrassem com o trabalho gratuito e com a
presença dos incontáveis fotografados que abasteceram a indústria (AZOULAY,
2019, p. 132).

Como correspondente da Magnum no Brasil por dois anos, Miguel Rio conhece as contingências do cargo e, ainda que tenha dele se beneficiado, não deixa de refletir criticamente sobre seus processos de produção. Em 1982, ele mudou-se para Paris e a sua situação como correspondente da Magnum ficou inviável, momento em que tornou-se nominee (nominado), uma categoria na qual o fotógrafo passa de dois a três anos como aspirante a membro da agência. Nessa época, realizou alguns trabalhos naquela cidade como, por exemplo, a documentação de bairros ocupados por africanos e antilhanos, bairros estes que estavam se tornando bastante degradados. Apesar da contundência e relevância do assunto, este tipo de documentação não costumava ser distribuído pela agência, pois "não era um tema que retrava o exotismo dos outros países", critica Rio Branco (apud SIZA, 2010, p. 109). Em diversas das suas entrevistas, o fotógrafo, no entanto, tece elogios à agência Magnum por ela, diferente de outras agências e veículos de comunicação, enxergar os seus membros como autores e thes dar liberdade para propor e desenvolver os seus projetos pessoais, embora nem sempre lhes permitisse controlar totalmente a edição e a apresentação dos mesmos. E é principalmente nestes processos de escolha e montagem das fotografias, nas páginas de uma reportagem ou nas de um livro autoral, que as construções dos discursos visuais são elaboradas por Rio Branco.

No final dos anos 1970, o Pelourinho encontrava em situação muito diferente daquela do passado, e também do presente. Desde meados do século XVI até o início do século XX, concentravam-se no ali as melhores moradias e o centro comercial e administrativo de Salvador. Entretanto, dos anos 1950 até o seu tombamento como Patrimônio da Humanidade e revitalização da sua área nos anos 1980 e 1990, o Pelourinho sofreu um forte processo de degradação devido à transferência das atividades econômicas para outras localidades da capital baiana, transformando o Centro Histórico em um local de criminalidade, violência e prostituição, assim como de moradias populares e reduto da cultura negra da cidade. É, portanto, nesse contexto que Rio Branco envolveu-se durante nove meses na documentação fotográfica e cinematográfica da comunidade do Maciel, registrando as ruínas arquitetônicas dos antigos casarões coloniais e retratando de maneira muita intensa, íntima e franca os seus moradores nas ruas e na porta de suas casas e, principalmente, algumas prostitutas em seus quartos. 
Este mergulho na realidade social do Pelourinho deu origem à exposição Nada levarei quando morrer aqueles que mim deve cobrarei no inferno (sic) que exibiu, em 1980, na Galeria Fotoptica, em São Paulo, e neste mesmo ano na Fotogaleria Funarte, no Rio de Janeiro, um conjunto de 50 fotografias coloridas das ruínas arquitetônicas do bairro e dos seus moradores, com destaque para as prostitutas que ali habitavam e trabalhavam. No ano seguinte, Rio Branco lançou o curta-metragem homônimo, filmado em $16 \mathrm{~mm}$ durante três dias, também no Pelourinho, cuja edição, além de trilha sonora com músicas brasileiras e estrangeiras, incluía parte das fotografias realizadas na primeira incursão do fotógrafo na região, em 1979. ${ }^{[2]}$ E finalmente, em 1985, o fotógrafo publica Dulce Sudor Amargo, seu primeiro livro com 80 fotografias de Salvador, sendo a maioria pertencente ao material produzido na comunidade do Maciel.

Ainda que as fotografias feitas em 1979 componham a parte central de Dulce Sudor Amargo, Rio Branco insere, principalmente no início de sua narrativa, novas imagens produzidas cinco anos depois em outras regiões de Salvador. De maneira geral, uma atmosfera de tranquilidade e paz predomina nas sequências iniciais do livro, pois trazem fotografias de diversas situações corriqueiras do cotidiano da cidade. No entanto, após esta introdução que apresenta uma visão amplificada da capital baiana por meio de aspectos generalizantes da sua cultura (pescadores e jangadas, candomblé, praia, barracas de diversão, capoeira, etc.), eis que surge um grupo de imagens menos palatáveis da dura realidade do Pelourinho realizadas nas ruas estreitas e nos ambientes fechados e sombrios dos casarões e prostíbulos deste bairro.

Os retratos de prostitutas, em sua maioria negras, predominam nesse conjunto de imagens. Elas são registradas de maneira direta, e quase sempre frontalmente, revelando assim a abordagem franca de Rio Branco, que não parece ter lançado mão do flagrante como estratégia de captura do "real", nem tampouco utilizado recursos ficcionais como, por exemplo, a direção dos fotografados ou a preparação das cenas. Além disso, a narrativa do livro propõe um sequenciamento e combinações de fotografias que articulam aspectos formais e semânticos e revelam as estratégias de seu autor para promover conexões subjetivas entre elas. Seja pelas tonalidades cromáticas, seja pelo tipo de iluminação ou mesmo pela escolha e forma com que objetos e pessoas são aproximados, Rio Branco constrói sequências e justaposições que evocam novos sentidos que vão além daqueles expressos nas fotos quando consideradas isoladamente. 


\section{OLHAR SOBRE O “OUTRO DO OUTRO”}

As semelhanças formais das imagens num dos dípticos de Dulce Sudor Amargo (FIG. 1) podem ser facilmente identificadas, seja pela iluminação oblíqua que entra pela portas deixando parte dos objetos ou dos personagens parcialmente sombrios, seja pela coloração amarelada ou azulada da fachada dos casarões ao fundo ou ainda pelo estilo barroco das balaustradas do parapeito nas sacadas das duas fotografias. Entretanto, o que nele se destaca, e que predomina nesse conjunto de imagens do livro, é a associação estabelecida entre os corpos das mulheres, muitas vezes marcados por cicatrizes, e a precariedade de suas moradias. Na imagem da direita, a personagem, possivelmente uma prostituta, encontra-se encostada em uma parede corroída pelo tempo. Com as mãos na cintura, ela parece ter erguido a camiseta e deixado os seios à mostra para posar com altivez para o fotógrafo, demonstrando segurança e tranquilidade mesmo em um ambiente violento, como sugere a imagem à esquerda ao mostrar, entre outras coisas, um revólver em uma sacada que, por sua vez, parece ser a mesma da foto ao lado.

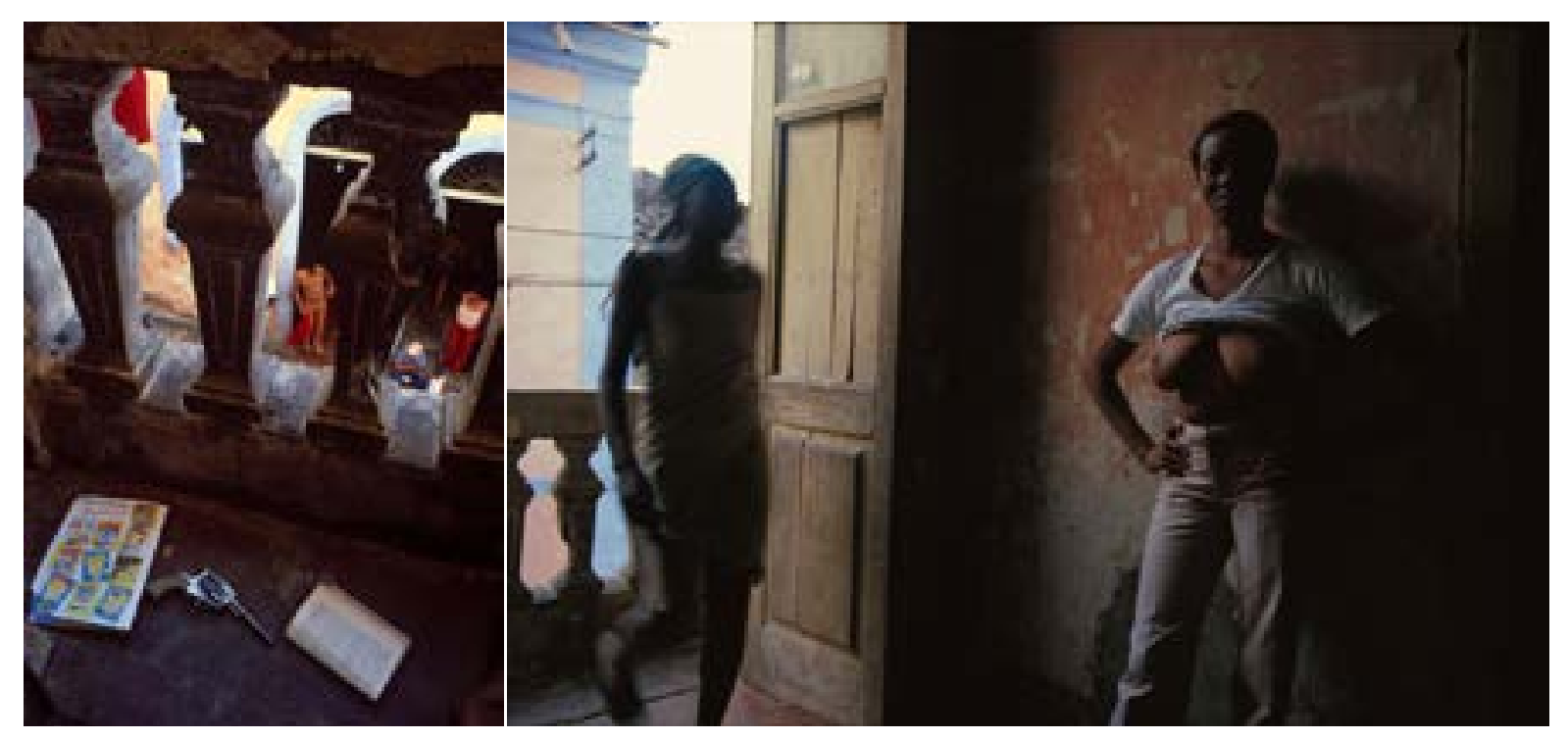

FIGURA 1: Sem título. Miguel Rio Branco

Fonte: RIO BRANCO (1985)

Aparentemente, não há flagrantes na produção dos retratos. Voluntariamente, as mulheres posam (ou performam) para as lentes de Rio Branco, que tampouco parece ter dirigido ou montado previamente as cenas. Como admite o fotógrafo, esta disposição para o trabalho advinha delas 
próprias que, "pediam para serem retratadas e faziam os nus", entregues posteriormente em formato de monóculos. Ele explica ainda que as fotos eram feitas pela manhã, quando

[...] todas estavam mais relaxadas; o lado pessoal estava mais presente do que o profissional, relacionado à noite, às drogas, à bebida e à sedução. Eram, portanto, as mulheres como sustentáculo de uma sociedade destruída pela ação do homem (RIO BRANCO apud BOUSSO, 2012, p. 22).

Diante da afirmação de Rio Branco de que as mulheres do Maciel eram "como sustentáculo de uma sociedade destruída pela ação do homem", poder-se-ia perguntar se as fotografias de Dulce Sudor Amargo, ao serem produzidas por um homem, cujas origem, formação e posição social eram bem distintas das delas, também não contribuiriam para a uma certa destruição social ao desumanizá-las ou objetificá-las pela maneira com que elas foram representadas (e publicadas) no livro? Trata-se de assunto delicado: a representação de corpos negros femininos a partir do olhar de um homem branco.

Sobre a condição e representação da mulher negra na sociedade, a filósofa e escritora Djamila Ribeiro (2020), enfatiza a existência na América Latina e Caribe de um olhar colonizador não apenas sobre seus corpos, mas também sobre seus saberes e produções. Em razão do histórico de invisibilidade, submissão e dominação pelos homens em sociedades patriarcais e racistas, Ribeiro ressalta a necessidade de as mulheres negras não apenas refutarem esse olhar colonizador, mas, principalmente, se autodefinirem. Com base nos estudos da filósofa francesa Simone Beauvoir e da escritora e teórica portuguesa Grada Kilomba, Djamila Ribeiro observa que se, para a primeira, a mulher (independente da raça) foi constituída como o Outro, já que vista como um objeto e, portanto, destituída de humanidade, para a segunda, a mulher negra ocupa uma posição de mais difícil reciprocidade, pois, numa sociedade suprematista branca, ao não ser nem branca nem homem, ela torna-se o Outro do Outro. Dessa forma, ao destacar a sofisticação na percepção que Kilomba traz sobre a categoria do Outro, Ribeiro salienta que esta dificuldade de reciprocidade coloca a mulher negra em um lugar ainda mais difícil do que os lugares da mulher branca e do homem negro, fazendo-a, então, experenciar "uma espécie de carência dupla, a antítese de branquitute e masculinidade", (RIBEIRO, 2020, p. 38).

Nesta posição social duplamente carente, as mulheres negras não apenas vivem uma situação em que as possibilidades materiais são menores, mas também têm dificuldade de serem vistas como sujeito, o que demanda, portanto, ações emancipatórias entre as quais Djamila Ribeiro destaca o "deslocamento do pensamento hegemônico e a ressignificação das identidades" a fim de se construir novos lugares de fala e dar visibilidade a sujeitos excluídos dessa normatização hegemônica. Citando a socióloga Patrícia Hill Collins, Ribeiro prossegue ressaltando que é necessário as mulheres negras se autodefinirem porque "definir e valorizar a consciência do próprio ponto de vista autodefinido frente a imagens que promovem uma autodefinição sob a 
forma de 'outro' objetificado" é uma forma importante de resistir à desumanização essencial aos sistemas de dominação", sistemas cuja norma pressuposta de comportamento é a dos homens brancos, para quem mulheres negras seriam um "outro negativo, a antítese virtual da imagem positiva" desses homens (COLLINS. 2016, p. 105 apud RIBEIRO, 2020, p.43-44).

Diante deste contexto, voltamos à indagação sobre a forma com que as mulheres do Maciel foram representadas nas imagens de Dulce Sudor Amargo. Se por um lado as fotografias do livro parecem originarem-se de uma prática fotográfica respeitosa, que envolvia o diálogo fotógrafo-fotografadas, como a proximidade mantida entre eles indica, por outro lado, tais imagens nos levam a pensar sobre o tipo de relação que travavam, nos impelindo a refletir criticamente sobre o lugar social de ambos e as formas escolhidas para representá-las. Assim, nesta negociação do fotógrafo com as modelos, é preciso apontarmos as distintas posições sociais ocupadas por ele e por elas.

Em síntese, as retratadas eram mulheres pobres, negras e habitantes de moradias populares ou casarões abandonados e localizados em uma região que, devido ao descaso público à época, tinha como marcas a criminalidade, a violência e a prostituição. Ou seja, eram mulheres vivendo à margem da sociedade em um ambiente em alto grau de degradação. Já do outro lado da câmera estava Miguel Rio Branco, homem branco, filho de diplomatas e, portanto, pertencente à alta classe social brasileira. Com formação cultural em diversos países do mundo, Rio Branco era, no Pelourinho do final dos anos 1970, mais um forasteiro que não apenas andava por uma região de casas e pessoas marginalizadas, como também lançava seu olhar sobre elas a fim de produzir uma documentação daquela realidade social.

Desse modo, apesar das possíveis nuances envolvidas nas abordagens fotográficas, Rio Branco, pelo sua posição social, lançava seu olhar sobre essas mulheres em situação de vulnerabilidade a partir de um local de "superioridade" - superior ao menos nesse modelo em que homens brancos, como lembra Djamila Ribeiro (2020, p. 44), "definem-se como sujeitos, os verdadeiros atores, e classificam as pessoas de cor e as mulheres em termo de sua posição em relação a esse eixo masculino branco". Além disso, embora fossem as protagonistas do ensaio fotográfico realizado em 1979, não se pode afirmar que mulheres do Maciel tenham se autodefinido nas imagens publicadas no livro em 1985, o que pressupõe o controle do seu processo de produção e edição, incluindo aí as múltiplas escolhas formais por meio das quais foram representadas.

No entanto, as definições e críticas ao trabalho de Miguel Rio Branco não são tão simples de serem feitas, pois sua inegável posição social de superioridade por si só não lhe impede, obviamente, ser empático e também não lhe impõe nem uma abordagem autoritária para com aquelas mulheres, nem tampouco escolhas estéticas e conceituais delimitadas por um "padrão colonizador" de olhá-las e documentá-las fotograficamente a ponto de, necessariamente, objetificá-las ou desumanizá-las. 

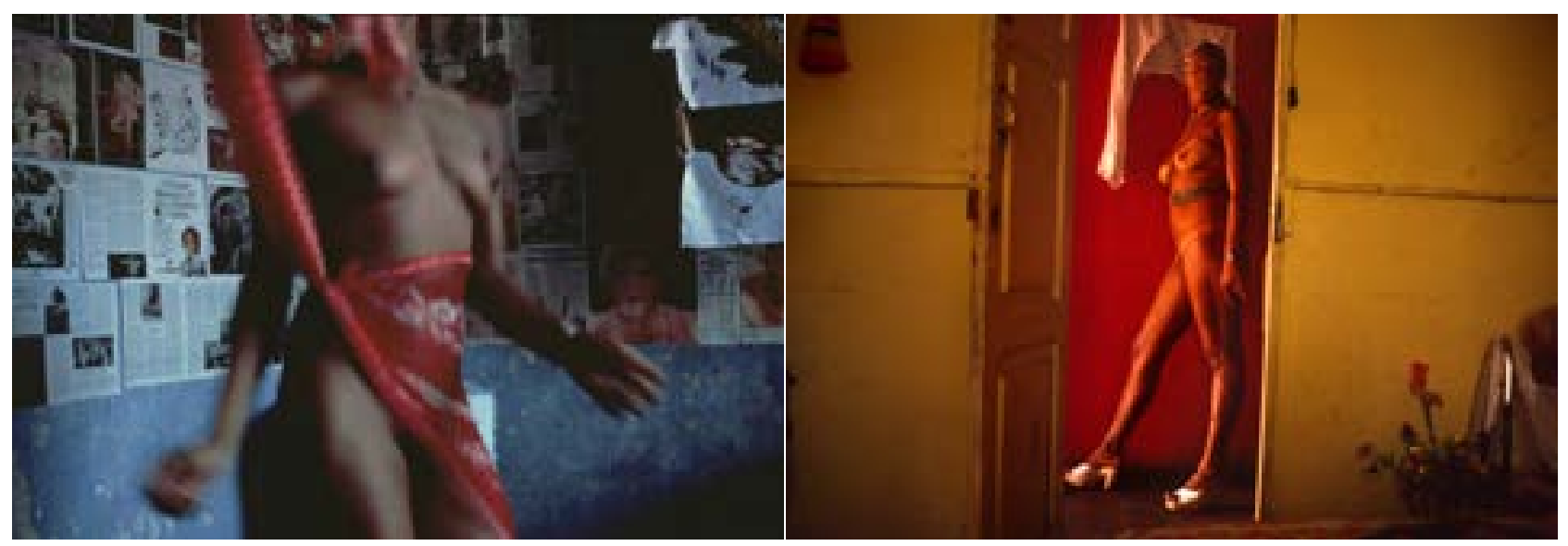

FIGURA 2: Sem título. Miguel Rio Branco

Fonte: RIO BRANCO (1985)

De fato, esse grupo de fotografias produzidas no Maciel é muito forte, mas não se trata de um ensaio realizado em torno apenas das dificuldades e do sofrimento de pessoas vivendo e trabalhando em condições precárias e que aborda exclusivamente sua situação de vulnerabilidade diante da dura realidade de desigualdade social daquela comunidade brasileira. Sem um sentido unívoco, mas, sim, com uma escala semântica oscilante, os retratos das mulheres no livro, além de não fazerem julgamento moral sobre o tema da prostituição - o que geralmente se vê em publicações conservadoras ou sensacionalistas -, também as mostram (FIG. 2), por vezes não identificadas ou descontraídas, em performances de sensualidade, exaltando a sexualidade e o erotismo que emanavam dos seus corpos e funcionavam como uma forma de resistência frente àquele ambiente degradado.

\section{CICATRIZ COMO METÁFORA}

Nas fotografias de Dulce Sudor Amargo, os corpos, especialmente os das prostitutas do Maciel, são representados como símbolos detonadores de sensações e questões diversas. Eles trazem inscritos em sua superfícies não apenas sinais da passagem do tempo, mas sobretudo marcas advindas da existência dessas mulheres em um universo muito particular como era aquele do Pelourinho no final dos anos 1970. Ou seja, além de rugas e a aspereza da pele, seus corpos exibem marcas das experiências por elas vividas, tornando-se, por isso, um terreno fértil 
para a comunicação e a expressão de sua condição no mundo. Com essa perspectiva, o fotógrafo soube enxergar e registrar a difícil condição social por elas vivida naquele ambiente sem, contudo, querer denunciá-la ou mesmo revelar a verdade sobre a sua individualidade, observando-as mais por aquilo tinham em comum: as cicatrizes na pele.

Como nota Paulo Sergio Duarte (2000), as cicatrizes das prostitutas singularizam esse grupo de mulheres, pois seus "corpos poderiam se confundir com qualquer outro corpo", não fosse por trazerem "literalmente à flor da pele, rastros de existência". Rastros que mostram como suas peles não passaram impunes pela dura experiência de viver desse lado da sociedade. O crítico e pesquisador reflete também sobre o simbolismo das cicatrizes e a dor que provocam não apenas na pele, como também na vida, no espírito daquelas que as levam:

\footnotetext{
[...] cada cicatriz tem um tempo e uma memória guardada na subjetividade dos portadores daqueles corpos e esse tempo é toda a eternidade: o instante da dor em que a carne foi cortada, a hemorragia, a cicatrização, o processo de incorporação no espírito da marca definitiva da violência sofrida ou voluntária (DUARTE, 2000, s/p).
}

Tendo provavelmente como causas a violência sexual, os acidentes de orgias, os rituais religiosos, as doenças ou ainda as brigas de rua, as cicatrizes presentes na pele da maioria das prostituas retratadas por Rio Branco mostram como o fotógrafo concentrou-se nessas marcas para documentar o universo, por vezes dramático, em que viviam, sem deixar de exaltar a força dos seus olhares e a beleza que pulsava dos seus corpos.

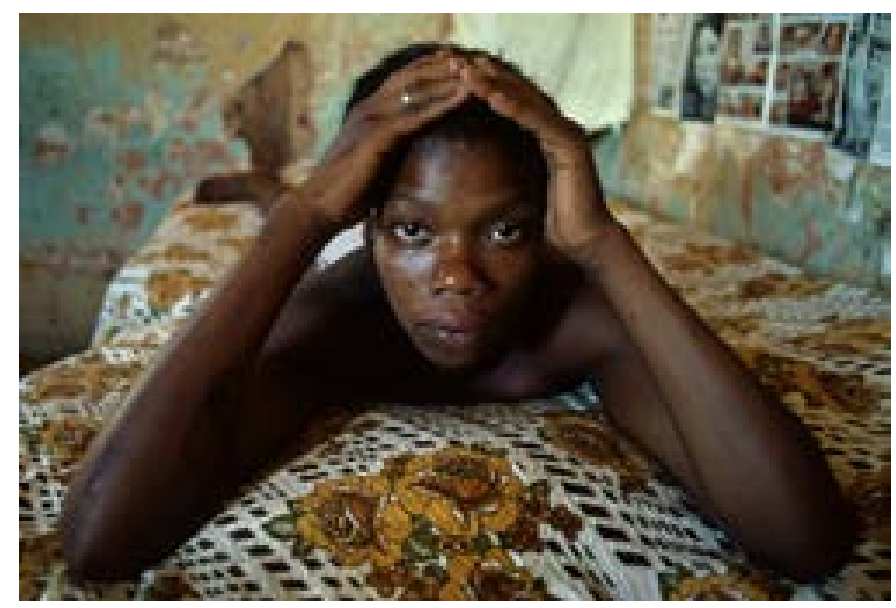

FIGURA 3: Sem título. Miguel Rio Branco Fonte: RIO BRANCO (1985) 
Em uma das fotografias desse conjunto (FIG. 3) uma mulher negra deitada com as mãos na cabeça e os cotovelos apoiados sobre o colchão olha para dentro das lentes do fotógrafo. Sua expressão é serena, mas forte. As marcas na pele, ou os "rastros de existência", podem ser observadas em seu rosto e, principalmente, em seus braços. Com formatos e tamanhos diversos, tais marcas são, talvez, de espinhas, de pequenos ferimentos casuais, de queimaduras de cigarro ou ainda de cortes mais graves a ela desferidos, como, por exemplo, uma cicatriz maior próxima ao seu cotovelo direito nos faz crer. Mas além do corpo e de suas cicatrizes, o enquadramento e composição desta e de outras fotografias nessa parte do livro não deixam de incluir a situação do ambiente que pode, por sua vez, ser comparada às condições de vida das suas personagens. Assim, o olhar do seu espectador, em uma leitura circular dos elementos presentes na imagem, transita pelas marcas do tempo tanto no corpo dessa mulher quanto na sua morada. Ou seja, ele circula ora pelas cicatrizes na sua pele, ora pelas paredes deterioradas do seu quarto, cuja pintura descascada se mistura às folhas de revistas nelas coladas que, além de ocultar parte dos rebocos, ainda serve como uma "janela", um extracampo que transportaria imaginariamente a modelo para outras realidades.

Para Guran (1998), o ato de fotografar se dá em um espaço muito curto de tempo, o que resume toda a singularidade e complexidade da fotografia. Em um trabalho de documentação, exige-se do fotógrafo o reconhecimento antecipado daquilo que se pretende registrar, ou seja, é necessário prever ou intuir aquilo que se quer representar. Segundo ele, nem tudo o que se vê é fotografável e pode ser traduzido de forma eficiente através da linguagem fotográfica, mas:

\footnotetext{
Por outro lado, uma das potencialidades da fotografia é a de destacar um aspecto particular, que se encontra diluído em um vasto e sequencial campo de visão, explicitando, através da escolha do momento e do enquadramento, a singularidade e transcendência de uma cena (GURAN, 1998, p. 91).
}

Diante das observações de Guran, é possível avaliarmos que, nos retratos das prostitutas feitos por Miguel Rio Branco, mais do que da escolha do momento - já que não há flagrante, mas pose -, foi através da escolha do enquadramento e, principalmente, das justaposições de imagens nas páginas do livro que fotógrafo conseguiu explicitar a singularidade e, sobretudo, a transcendência das cenas. Ao escolher determinados enquadramentos e justaposições que destacam tanto o olhar direto e franco das modelos quanto as cicatrizes, a beleza e a sensualidade dos seus corpos juntamente com as paredes deterioradas dos ambientes, promovendo assim articulações subjetivas eles, o fotógrafo intuiu, dir-se-ia, essas marcas do tempo nas pessoas e nas coisas como o fundamento primordial das metáforas visuais ambíguas presentes no livro: dor e prazer, drama e erotismo, opressão e resistência, pobreza e altivez.

Em suma, é por meio dessas associações metafóricas que os meros documentos fotográficos de Miguel Rio Branco se tornam "imagens-poema", como assim Duarte definiu suas imagens que 
"se envolvem com os indivíduos que vivem à margem, mas que neles alcançam o élan vital e os apresentam como gente saturada de humanidade" (DUARTE, 2000, s/p).

\section{O CORPO AMBÍGUO}

As fotografias na parte central de Dulce Sudor Amargo formam uma sequência marcante e são abaixo apresentadas tais como aparecem no livro (FIG. 4). Elas sugerem a pluralidade de sentidos, incitando a interpretação de quem as observa. E fazem isso ao sacodir a visão simplista que as relacionaria unicamente à prostituição, à miséria e ao sofrimento, direcionando seu espectador para outras possibilidades de interpretação daquele universo fotografado. Se por um lado não escondem o drama e a dor de pessoas que vivem em moradias precárias e trazem na pele diversas cicatrizes oriundas, provavelmente, de cortes, queimaduras e doenças, por outro lado estas fotografias (assim como a maioria dos retratos das prostitutas apresentadas no livro) também exaltam os seus momentos de prazer e afetividade. Nesse sentido, o que se vê é uma desconstrução da suposta mensagem objetiva e unívoca na representação fotográfica que, nesses retratos, parte de temas básicos (prostituição e desigualdade social) para abordar questões mais amplas e subjetivas, não se limitando a tratar unicamente das intempéries na vida de pessoas de camadas sociais economicamente desfavorecidas. 


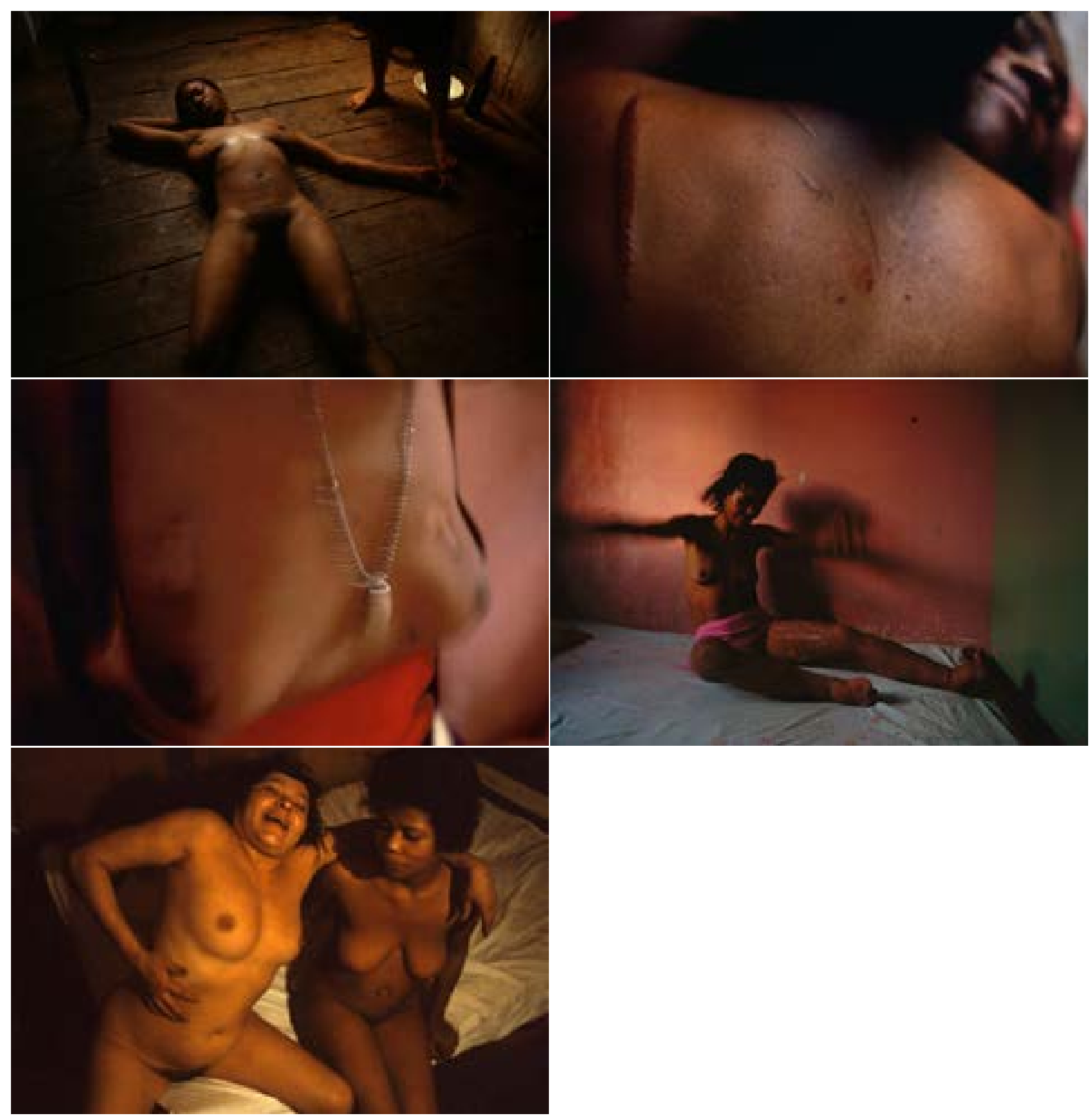

FIGURA 4: Sequência de fotografias de Dulce Sudor Amargo. Miguel Rio Branco Fonte: RIO BRANCO (1985)

O corpo é um elemento-chave na obra de Rio Branco que, a partir dele, constrói boa parte das metáforas visuais de suas narrativas. E em Dulce Sudor Amargo, as associações metafóricas criadas pelas justaposições de imagens não se restringem apenas às paredes corroídas e aos corpos humanos, mas se estendem também aos corpos de animais. Seguindo, então, essa linha associativa, 
o livro apresenta ainda diversas fotografias de cobra, galos e, principalmente, cães que aparecem em meio às pessoas, nas ruas, na porta de casas e igreja. Dentre elas, destaca-se um dos trabalhos mais famosos de Rio Branco, que não apenas aparece nessa publicação, como também é reutilizado em outros projetos de exposição, livro ou projeção. "Dog man" e "Man dog" (FIG. 5) são os títulos das imagens que compõem, provavelmente, um dos momentos mais fortes de Dulce Sudor Amargo, pois, de forma extremamente crua e visceral, expõem a dramática condição de abandono e miséria de um cachorro e um homem que, no entanto, lutam para sobreviver.


FIGURA 5: "Dog man" e "Man dog". Miguel Rio Branco

Fonte: RIO BRANCO (1985)

Domesticado há milhares de anos e presente em quase todas as civilizações no mundo, o cão é um bicho extremamente resistente e leal ao dono. Em uma situação na qual o próprio homem - nesta foto generalizando a condição social dos moradores de rua do Pelourinho - encontravase jogado à sorte, sujeito às mais diversas forças de opressão que ali prenominavam na época, ao cachorro da imagem ao lado também não lhe restaria, supõe-se, muitas opções senão se entregar ao acaso. Entretanto, cá os vemos resilientes. Dormindo deitados sobre calçadas sujas de ruas quaisquer do bairro, ambos são registrados por Rio Branco em posição semelhantes e a partir de ângulos aéreos (em plongé) e iluminação muito similares. Além desses aspectos formais que os aproximam, eles ainda compartilham, com persistência, um estado comum de penúria que é evidenciado pelas feridas de micoses na pele do cão e pelas roupas sujas e rasgadas do homem. Pela força estética que possuem, estas fotos já seriam impressionantes se observadas isoladamente, no entanto, quando justapostas, elas "se contaminam" e o impacto visual do díptico, ao invés de chocar o espectador no que toca à miserabilidade e fraqueza do homem, o faz, por outro lado, refletir sobre a resiliência humana aqui diretamente equiparada à força e 
resistência de um cachorro abandonado diante das dificuldades de sobreviver sozinho nas ruas.

Após as últimas fotografias dessa parte central do livro, que apresentam cães, galos e pessoas registrados em meios aos escombros do Pelourinho com cores quentes e sob a penumbra dos casarões, a narrativa é finalizada com mais algumas imagens de praia, ruas, mercados e personagens da vida cotidiana de Salvador, nas quais a iluminação direta pelos raios de sol e as cores mais frias como o branco e o azul vistas no começo do livro voltam a aparecer. São cenas mais leves da capital baiana que, nesse momento, retiram o leitor de um certo tipo de enclausuramento provocado pelas ruas estreitas e quartos sombrios daquele bairro e o reconduzem novamente para uma visão mais ampla, denotando claramente a existência de uma história sobre uma cidade real com personagens reais vivendo em condições e lugares específicos e identificáveis nas imagens do livro.

É inegável que toda a narrativa seja permeada por combinações formais (luz e cores saturadas), por associações temáticas subjetivas (montagem dos dípticos e mistura de séries distintas) e por momentos de quebras e continuidades (alternância de assuntos e questões) que abstraem parcialmente os temas centrais mais óbvios como prostituição e desigualdade social e evidenciam a estética expressiva, o olhar pessoal e a capacidade de construção poética do seu autor. Porém, são especialmente as fotografias feitas no Maciel, com sua carga semântica marcadamente ambígua, que revelam com maior contundência a singularidade poética dessa documentação ao abordar paradoxalmente o drama e a austeridade das prostitutas do Maciel, trazendo mais questões do que afirmações sobre a sua realidade. Com isso, o livro, a despeito de sua forte carga humanista, acaba se diferenciando dos relatos realistas e, por vezes, denuncistas do fotojornalismo internacional. Além disso, as imagens dessas mulheres tornam também Dulce Sudor Amargo uma obra pouco convencional para os padrões clássicos das reportagens brasileiras da época, nas quais as fotografias eram usadas, em geral, ou como arma de denúncia das desigualdades sociais ou ainda como ilustrações dos textos que exaltavam muitas das vezes o lado pitoresco das cidades brasileiras como, por exemplo, as representações de uma Salvador de praia, música, festa, religiosidade e sem grandes conflitos sociais.

\section{CONSIDERAÇÕES FINAIS}

Se a vertente da fotografia voltada, desde anos 1950, à captação da realidade do brasileiro foi por um tempo a única existente no Brasil ou pelo menos aquela que teria encontrado um nicho 
definido, como observou Chiarelli (1999), ela, entretanto, tem se defrontado nas últimas décadas do século XX com trabalhos como este de Miguel Rio Branco que passam a propor novas formas de documentação associadas aos processos criativos da arte e à subversão das noções de prova e testemunha da verdade atribuídas ao documento fotográfico. Nota-se, então, um momento de virada na história da fotografia brasileira, pois, o fotógrafo se utiliza de novas estratégias estéticas para criação de suas poéticas que se distanciam das narrativas factuais e das táticas de denúncia do fotojornalismo que eram e, por vezes, ainda são utilizadas por seus contemporâneos nas revistas e jornais do Brasil. Ademais, ele rompe com as representações exóticas do Outro predominantes entre os fotógrafos viajantes que percorreram o território brasileiro durante a segunda metade do século XIX.

Contudo, como fotógrafo e fotografadas ocupavam posições sociais distintas e elas - mesmo para ele posando voluntariamente -, não possuíam o controle de produção e publicações de suas imagens, não se pode afirmar que se trata de processo decolonizador e de autodefinição na representação de seus corpos. Por outro lado, Rio Branco conseguiu, por meio de uma relação dialógica com o consentimento das modelos, produzir metáforas visuais ambíguas construídas a partir dos ambientes precários e das cicatrizes e sensualidade dos seus corpos registrados em momentos de descontração, prazer e afetividade, e assim transformar um tipo de performatividade que estas mulheres desempenhavam em um discurso poético e político sobre a realidade e os processos de marginalização de determinados grupos sociais que, em suas imagens, são representados em estado de altivez e resistência, mesmo sendo historicamente estigmatizados e vivendo em constante situação de ameaça e opressão.

Ao se discutir poder, visibilidade e, consequentemente, quem tem o monopólio de construir representações, pode-se ainda inferir que este processo de produção do ensaio no Pelourinho pode, de fato, mascarar uma possível violência nestas relações do fotógrafo com as mulheres. Afinal, por que elas são tema de interesse?

De todo modo, há nos trabalhos de Miguel Rio Branco, não apenas em Dulce Sudor Amargo, a busca por uma identidade nacional que faça frente às imagens produzidas pelo olhar estrangeiro com base em nosso passado colonial. Diante de uma complexa história de formação da sociedade brasileira, Rio Branco entendeu que era preciso representar o Outro liberto não apenas de uma visão externa e estereotipada dos viajantes do século XIX, mas também de uma linguagem pretensamente objetiva e realista como a utilizada pela imprensa internacional e brasileira com seus registros dos dramas sociais e da violência do país. Tratar-se-ia, portanto, não de captar o Outro com o auxilio da câmera fotográfica, mas de construir ética e artisticamente uma representação poética dos sujeitos fotografados, sejam eles prostitutas, favelados, moradores de ruas, todos vivendo à margem de um sistema dominante e opressor que impera até os dias atuais no Brasil. 


\section{REFERÊNCIAS}

ARAGO, François Dominique. Report. In: Alan Trachtenberg (ed.) Classic Essays on Photography. New Haven, CT: Leete's Island Books, 1980, p. 15-25.

AZOULAY, Ariella. Desaprendendo momentos decisivos. Zum, n. 17, p: 117-137, 2019.

BOUSSO, Daniela. Daniela Bousso entrevista Miguel Rio Branco. In: BOUSSO, Daniela, SANTOS, Angela (Orgs). Maldicidade - Marco Zero. São Paulo: Imprensa Oficial; Museu da Imagem e do Som-SP/Governo do Estado de São Paulo, 2012.

CHIARELLI, Tadeu. Arte Internacional Brasileira. 2. ed. São Paulo: Lemos Editorial, 1999.

COLLINS, Patricia Hill. Aprendendo com a outsider within: a significação sociológica do pensamento feminista negro. Sociedade e Estado, v. 31, n. 1, p. 99- 127, 2016. Disponível em: <https://goo.gl/RmjB7R>. Acesso em: 05 nov. 2020.

DUARTE, Paulo Sergio. Pele do Tempo. In: RIO BRANCO, Miguel. Pele do Tempo. Rio de Janeiro: Centro de Arte Hélio Oiticica, 2000.

FERNANDES JUNIOR, Rubens. Labirintos e Identidades: panorama da fotografia no Brasil [1946-987. São Paulo: Cosac\& Naify, 2003.

GURAN, Milton. A 'Fotografia Eficiente’ e as Ciências Sociais. In: Ensaios Sobre o Fotográfico. (Org. Luiz E. R. Achutti). Porto Alegre: Prefeitura Municipal, 1998, p.87-99.

HERKENHOFF, Paulo. A Espessura da Luそ: fotografia brasileira contemporânea. São Paulo: Câmara Brasileira do Livro (Brasil: Confluência de Culturas - 46ª Feira do Livro de Frankfurt, 1994).

KOSSOY, Boris. Dicionário Histórico-Fotográfico Brasileiro: fotógrafos e ofício da fotografia no Brasil (1833-1910). São Paulo: Instituto Moreira Salles, 2002.

KOSSOY, Boris; ENTLER, Ronaldo. Fotografia brasileira: nova geração. Photo, n. 329, abr. 1996. Disponível em: <http://goo.gl/oifMXf>. Acesso em: 04 jul. 2014.

LUGON, Olivier. Le Style documentaire: D’August Sander à Walker Evans, 1920- 1945, Paris: Macula, 3a ed., Paris, 2011.

MAGALHÃES, Ângela e PEREGRINO, Nadja Fonseca. Fotografia no Brasil: um olhar das origens ao contemporâneo. Rio de Janeiro: FUNARTE, 2004.

RIBEIRO, Djamila. Lugar de fala. São Paulo: Sueli Carneiro; Editora Jandaíra, 2020. 
RIO BRANCO, Miguel. Dulce Sudor Amargo. México D.F: Fondo de Cultura Económica, 1985.

SIZA, Tereza. Miguel Rio Branco habla com Tereza Siza. Madrid: La Fábrica y Fundación Telefónica, 2010. (Colección Conversaciones con Fotógrafos, p. 87-127).

SOUSA, Jorge Pedro. Uma História Crítica do Fotojornalismo Ocidental. Florianópolis: Letras Contemporâneas, 2004.

[1] De acordo com o seu site oficial, o artista possui um total de 16 livros publicados, sem contar os diversos catálogos editados por ocasião de suas exposições nacionais e internacionais. O último deles, intitulado Maldicidade, foi publicado em 2014, também pela editora Cosac Naify. Disponível em:<http://www.miguelriobranco.com.br $>$. Acessado em: 10 abril de 2019.

[2] Com o filme Nada levarei quando morrer aqueles que mim deve cobrarei no inferno, Miguel Rio Branco ganhou o Prêmio de Melhor Fotografia no Festival de Cinema de Brasília, em 1981, e o Prêmio Especial do Júri e da Crítica Internacional do XI Festival Internacional de Curta-Metragem e Documentários de Lille, na França. 